\title{
Coastal Vegetation Database of North-Western Seas of Russia
}

\author{
Valentin Golub, Alexey Sorokin, Natalia Grechushkina, Lyudmila Nikolaychuk \& \\ Viktoria Bondareva
}

\begin{abstract}
The structure and content of the Coastal Vegetation Database of North-Western Seas of Russia (GIVD ID EU-RU-004) is presented. All available phytosociological relevés from coasts of Barents Sea, White Sea and Baltic Sea have been collected and stored in a TURBOVEG 2.88 database. At present 1,500 relevés are available in the database. The data are mainly used for vegetation classification.
\end{abstract}

Keywords: Baltic Sea; Barents Sea; coastal vegetation; ecoinformatics; phytosociological database; White Sea.

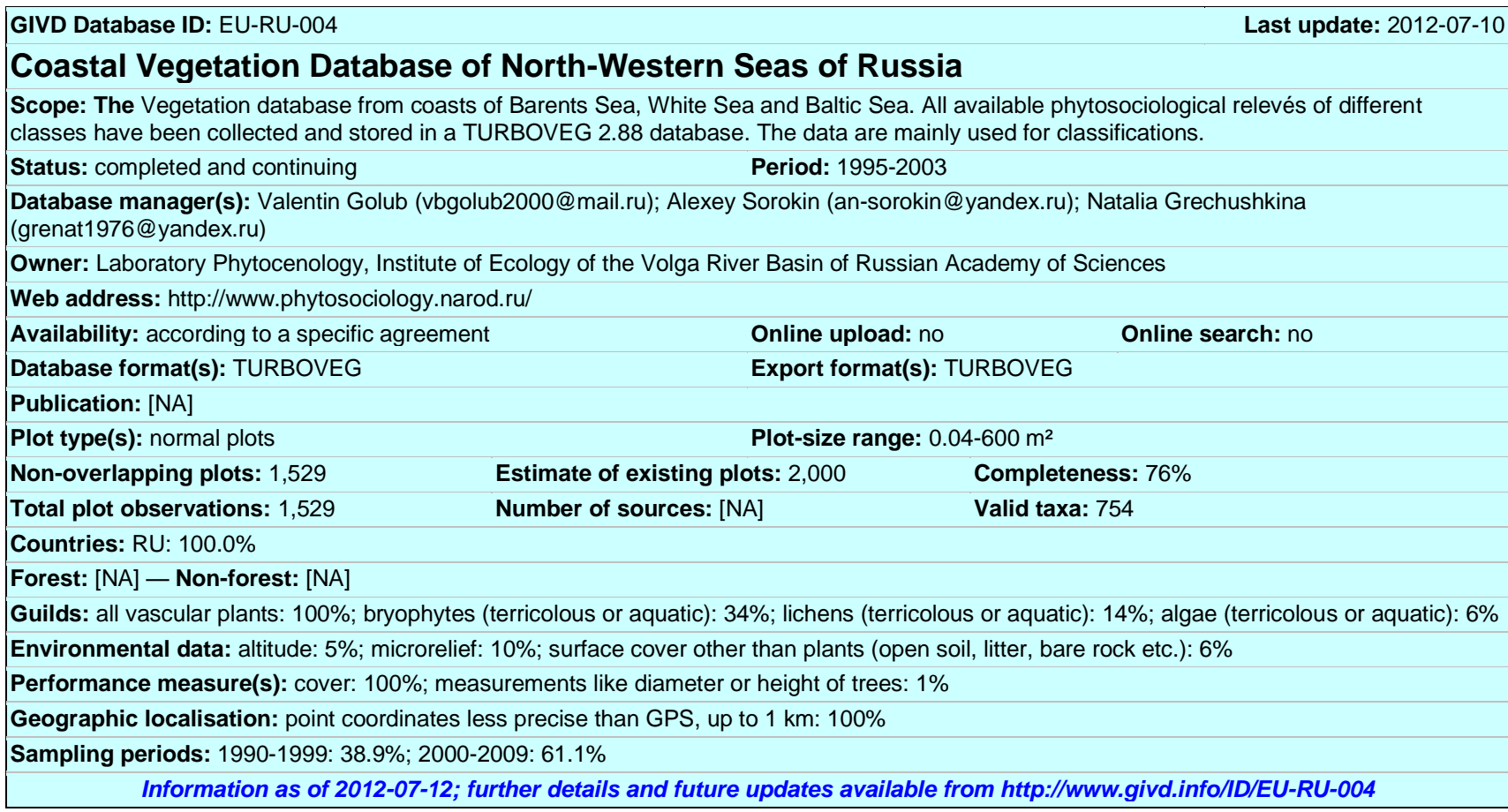

Valentin Golub (vbgolub2000@mail.ru), Alexey Sorokin* (an-sorokin@yandex.ru), Natalia Grechushkina (grenat1976@yandex.ru), Lyudmila Nikolaychuk (vbgolub2000@mail.ru), Viktoria Bondareva (victoria_bondareva@ rambler.ru)

Laboratory of Phytosociology, Institute of Ecology of the Volga River Basin of Russian Academy of Sciences, Komzina str. 10, 445003 Togliatti, RUSSIA

*Corresponding author 